\title{
Attention to ideas! Exploring idea survival in internal crowdsourcing
}

Idea survival in internal crowdsourcing

\author{
Fausto Di Vincenzo \\ Department of Economic Studies, G. d'Annunzio University, Pescara, Italy \\ Daniele Mascia \\ Department of Business and Management, LUISS Guido Carli, Rome, Italy, and \\ Jennie Björk and Mats Magnusson \\ Department of Machine Design, KTH Royal Institute of Technology, Stockholm, \\ Sweden
}

\begin{abstract}
Purpose - This paper analyzes how the distribution and structure of employees' attention influence idea survival in an organizational internal crowdsourcing session.

Design/methodology/approach - Data from an online internal crowdsourcing session carried out within a multinational company with headquarters in Sweden were used to explore how idea attention influenced idea survival.

Findings - Our findings indicate that the positive relationship between attention allocation and idea survival is mediated by idea appreciation, i.e. positive comments and suggestions that employees provide in response to ideas. In addition, we find that competition for attention negatively moderates the relationship between idea attention and positive comments. Finally, our results indicate that ideas are more likely to survive if they are submitted earlier in the crowdsourcing process and when the elapsed time since previously posted ideas in the session is longer.

Practical implications - This study provides organizers of internal crowdsourcing sessions with new insights about factors influencing idea survival and about potential systematic biases in idea selection due to timing and competition between ideas.

Originality/value - This paper contributes to the literature highlighting the relevance of attention-based theory in the context of crowd-based creativity and innovation management.
\end{abstract}

Keywords Ideation, Attention, Internal crowdsourcing, Competition for attention, Comments

Paper type Research paper

\section{Introduction}

Organizations are increasingly concerned with innovation, and in order to create new and profitable businesses, services, products, and processes, or improve existing ones, a rich flow of ideas stands out as a critical prerequisite. Creativity, in terms of the ability to create knowledge that is both new, i.e. original or unexpected, and useful, i.e. appropriate for the user, is increasingly seen as a critical source of sustainable competitive advantage for organizations (Amabile, 1996). At the same time, organizations are experiencing profound changes in the way innovation is developed and fostered, shifting from more traditional mechanisms for idea generation to new forms of open suggestion (Bogers et al., 2017; Van Knippenberg et al., 2015; Van den Ende et al., 2014; Schulze and Hoegl, 2008). In the past, many firms relied upon cadres of professional inventors to foster innovation. More recently, they

(C) Fausto Di Vincenzo, Daniele Mascia, Jennie Björk, Mats Magnusson. Published by Emerald Publishing Limited. This article is published under the Creative Commons Attribution (CC BY 4.0) licence. Anyone may reproduce, distribute, translate and create derivative works of this article (for both commercial and non-commercial purposes), subject to full attribution to the original publication and authors. The full terms of this licence may be seen at http://creativecommons.org/licences/by/4.0/ legalcode.
Received 25 March 2019 Revised 30 September 2019 4 December 2019 Accepted 20 December 2019 
have started to engage both internal and external individuals to contribute to ideation (Van Knippenberg et al., 2015; Dahlander and Piezunka, 2014; Piezunka and Dahlander, 2015).

Whereas the open innovation paradigm has emphasized the role that external individuals outside the boundaries of firms play in innovation generation and development (Bogers et al., 2017; Piezunka and Dahlander, 2015; Bayus, 2013; Dahlander and Magnusson, 2005; Di Gangi et al., 2010; O'Mahony and Lakhani, 2011), internal crowdsourcing emphasizes employees as the main source of ideation and innovation (Malhotra et al., 2017). Especially in large organizations, internal crowdsourcing can be used as a fruitful means to leverage the innovation potential of employees, allowing them to collectively contribute with their ideas and knowledge (Bjelland and Wood, 2008; Kijkuit and van den Ende, 2010; Bayus, 2013; Reitzig and Sorenson, 2013; Malhotra et al., 2017).

The extant research on crowdsourcing has also recently analyzed the different models and techniques that can be used for internal crowdsourcing, such as idea campaigns, jams, or online sessions (e.g. Bjelland and Wood, 2008); how these models encourage employees to generate as many ideas as possible (e.g. Benbya and Van Alstyne, 2010); and how certain characteristics of ideas (e.g. number of words used to express the ideas) and ideators (e.g. expertise, number of suggestions provided) affect idea implementation (Schemmann et al., 2016). Yet, much less explored are the very underlying mechanisms of internal crowdsourcing. As highlighted in a recent literature review by Ghezzi et al. (2018), knowledge about the crowdsourcing process, and its mechanisms of competition and collaboration, is still limited. In particular, we know little about how competition for attention affects the ideation process in internal crowds, and there is an apparent lack of studies exploring how temporal patterns of attention allocation around certain ideas can influence ideation survival in crowdsourcing initiatives.

In this study, we draw on the "Theory of Attention" (Ocasio, 1997; 2011) to illuminate how the distribution and structure of employees' attention influence idea survival in an organizational crowdsourcing session. According to attention theory, crowdsourcing sessions can be viewed as systems of collective attention, and the manner in which attention is structured and distributed assumes relevance in ideation processes (Zhu et al., 2017; Malhotra and Majchrzak, 2014; Dahlander and Piezunka, 2014). We provide a threefold contribution to prior literature on internal crowdsourcing and ideation. First, we corroborate previous studies on ideation process by showing that idea attention and idea appreciation are related to idea success in internal crowdsourcing. Furthermore, we add to this line of research by exploring how the presence of competition for attention moderates the relationship between idea attention, idea appreciation, and ideation success. Finally, we argue that the effect of attention allocation on idea success is affected by temporality, i.e. when employees focus their attention on others' ideas. In this paper, we consider idea survival as a proxy of ideation success, rather than the actual implementation of the idea in the form of new products, processes and services, because it represents the early stages of innovation and can be seen as the most direct outcome of crowdsourcing sessions.

Taken together, earlier studies point to the potential benefits organizations can gain, in terms of more and better innovation ideas, by engaging their employees in collective ideation activities such as innovation jams. However, extant theory has so far not explicitly investigated the competitive dynamics as well as temporal conditions regarding attention that are created by internal crowdsourcing and how they may influence the probability of actually generating new and valuable innovation ideas. Hence, there is a need to further our understanding of the role attention plays in internal crowdsourcing. More specifically, the aim of this paper is to investigate how competition for attention and temporality of attention allocation influence idea survival, thus broadening previous research findings on ideation process in internal crowdsourcing. 
Addressing this topic is not only of theoretical interest for understanding how individuals decide on which problems and opportunities to focus their attention, but is also of importance for innovation practice as an increasing number of organizations frequently rely on internal crowdsourcing to trigger creativity and facilitate knowledge sharing among their employees.

The article is structured as follows. First, we introduce the theoretical background and formulate testable research hypotheses. Thereafter, the research setting and methods used are described, followed by results and analysis. Finally, the findings of the study are presented and implications for theory and practice are discussed.

\section{Theoretical background and hypotheses}

The key objective in the ideation process is to identify and develop ideas that can be turned into successful innovations, at the same time as non-valuable ideas are sorted out, in order not to expend more resources on them than necessary. This process of idea selection can however turn out to be less rational than we might imagine due to possible distortion effects caused by individuals who are influenced by other members. This risk is arguably more substantial in crowdsourcing than in a more structured and formal ideation process (Malhotra et al., 2017). Crowds are to a high degree self-organizing and display emergent patterns of idea creation and commenting behaviors (Colombo et al., 2011). A consequence of this is that individuals in crowds are more likely to be influenced by the behaviors of other crowd members, in terms of what ideas they interact with and what opinions they express. A key factor that can at least partly explain potential biases in crowdsourcing is the nature of human attention, something that has been emphasized in the innovation management literature by Van de Ven (1986). In external crowds, individuals follow their own preferences, but they are simultaneously influenced by the behaviors of other crowd members, and may knowingly or unknowingly replicate the behaviors of others. This is arguably even more problematic in firm-internal crowds. On the one hand, employees may feel that they are expected by colleagues and managers to actively contribute, and their actions are normally visible to others in the company. Consequently, they are driven to participate based not merely on their own intrinsic motivations, but also by perceived expectations from other organizational members. On the other hand, in internal crowdsourcing participants are usually expected to engage in the ideation activities during work hours, when they also have other tasks to perform, resulting in a more direct competition for their - often scarce - available time. Recently, more works focusing explicitly on attention have attracted interest in the broader innovation management research community (Beretta, 2019; Chen et al., 2020; Haas et al., 2015; Dahlander and Piezunka, 2014), and we now turn to an exposition of this stream of research.

Attention-based theory pivots around the fundamental tenet that attention is a scarce resource (Ocasio, 1997; 2011). Organizational scholars have devoted much effort to investigating how and why individuals allocate attention toward certain targets and not others, underscoring that "the cognition and action of individuals are not predictable from the knowledge of individual characteristics but are derived from the specific organizational context and situations that individual decision makers find themselves in" (Ocasio, 1997, p. 189). Evidence suggests that managers' attention allocation is conveyed by both industry-level events (e.g. Nigam and Ocasio, 2010; Cho and Hambrick, 2006; Hansen and Haas, 2001) and more internal factors (Bouquet and Birkinshaw, 2008), and that patterns of attention allocation can have effects for innovation processes at individual and organizational level (Dane, 2013; Knudsen, 2011).

Recently, the crowdsourcing literature has started recognizing the importance of the cognitive dimension enhanced by crowdsourcing, focusing on how employees and other contributors spontaneously allocate their attention in the crowd (Zhu et al., 2017; Piezunka and Dahlander, 2015; Dahlander and Piezunka, 2014). In internal crowdsourcing, innovation is primarily stimulated by ideas and suggestions shared by employees. But comments that Idea survival in
internal
crowdsourcing 
employees provide in response to their colleagues' ideas are other relevant stimuli to innovation, because it is through these contributions that existing ideas are further developed. Moreover, for employees participating in internal crowdsourcing activities, the expectation from colleagues and managers to actively contribute with ideas and feedback arguably competes with the need to perform other work activities, and thus creates a potential attention problem. Seen through the lens of attention theory, it becomes possible to explain why certain ideas and innovations are more likely to be successful in internal crowdsourcing in terms of patterns of attention allocation in crowdsourcing sessions (Zhu et al., 2017; Reitzig and Sorenson, 2013; Afuah and Tucci, 2012; Jeppesen and Lakhani, 2010). As the basic aim of internal crowdsourcing is to generate innovation ideas in an effective and efficient way, an improved understanding of factors influencing the survival of ideas is of value for both innovation research and practice. We will now turn to an exposition of such key factors identified in the extant literature, leading to the generation of a number of hypotheses.

\section{Idea attention and idea survival}

In general, the higher the number of actors involved in crowdsourcing, and as far as their contributions proliferate in the crowd, the more employees have to decide which initiatives to focus their attention on. In other words, the activity generated around ideas during the internal crowdsourcing certainly attracts the attention of employees, but at the same requires some effort to focus their energy and attention on a limited number of ideas.

Research has shown that idea success is related to how employees allocate their attention to certain ideas in the crowd. In particular, the number of comments and suggestions may be interpreted by employees as a signal of the high potential that ideas have in the crowd (Reitzig and Sorenson, 2013). A study conducted by (Di Gangi and Wasko, 2009) found that ideas that received more votes were more likely to be implemented by the company. In another recent study, Schemmann et al. (2016) found that more popular ideas, i.e. ideas voted by a large group of individuals, were more likely to be favorably considered by managers and then implemented in the firm.

Attention allocation through comments and suggestions also facilitates knowledge integration in internal crowdsourcing sessions. Malhotra and Majchrzak (2014) suggest that ideas with competitive advantage potential are more likely to surface when the crowd enhances knowledge integration through sharing (generating ideas, examples, facts, or commenting) and highlighting (promoting others' comments, appreciating others' ideas). Hence, high levels of attention around ideas can be decisive for the activation of these knowledge integration mechanisms, which, in turn, affect the likelihood of idea survival in crowdsourcing sessions.

In light of these arguments, we develop the following research hypothesis to confirm the results reported in previous studies on ideation in internal crowds:

HP1. Idea attention is positively related to idea survival in internal crowdsourcing.

\section{The mediation effect of idea appreciation}

The number of comments and suggestions provided on posted ideas, however, provides only a partial explanation of how employees and managers allocate their attention in the crowd. Attention research has widely investigated how and why individuals in organizations direct attention toward certain targets and not others (Weick and Sutcliffe, 2006).

Research on internal crowdsourcing has documented that comments and suggestions provided in online tools for innovation may vary substantially, both in terms of structure (e.g. length of comments) and analytical content (level of criticism, positive vs negative comments, etc.) (Malhotra and Majchrzak, 2014; O'Leary, 2016). For example, in a study on 
individuals' attention in a dynamic work setting, Dane (2013) reports that the quality of attention allocation is related not only to the number of stimuli, feedback and comments that an idea receives, but also - and in combination with - the type and content of the comments attracted by the idea. In a similar vein, in a study conducted in a crowdsourcing competition designed to elicit directions for Canada's digital future, O'Leary (2016) documents that the number of votes ideas receive in the crowd is statistically significantly related to the extent to which the sentiment of comments provided is positive.

The content of comments is important for idea success because it predicts the quality of attention that employees and managers allocate in the crowd (Van Knippenberg et al., 2015). In particular, employees' contributions providing encouragement, support, and positive criticism may serve a signaling function to participants in the crowd, providing legitimacy and recognition to those ideas that receive more positive comments (Di Gangi and Wasko, 2009). Moreover, positive suggestions offer important indications to both organizational managers and idea evaluators about which ideas are considered more valuable and relevant by the community of participants, resulting in more favorable judgment and feedback (Rueda et al., 2005). While previous research has documented a direct and positive relationship between idea appreciation and idea success, in light of the above reasoning we hypothesize that idea appreciation in the crowd, i.e. the number of positive suggestions and comments an idea receives, mediates the impact of idea attention on idea success. More formally:

HP2. Idea appreciation mediates the relationship between idea attention and idea survival.

\section{The moderation effect of competition for attention}

During crowdsourcing sessions, individuals and groups participate in creative processes in an iterative fashion. Employees develop ideas, present them to the group, learn from the group, work out issues independently, and then return to the group to further modify and enhance their ideas. In this context, the rational process of allocating attention unfolds through the complex interdependencies linking organizational members and ideas (Bayus, 2013).

People may engage in the innovation process by providing comments on one or more ideas. In this situation, employees start sharing their interest, attention and subsequent contributions regarding these different ideas (Schemmann et al., 2016). If, on the one hand, tools like internal crowdsourcing can increase the possibilities for people to share ideas, information and comments, on the other hand a consequence is that it also increases competition for attention (Haas et al., 2015; Sullivan, 2010).

As stated by Jeppesen and Lakhani (2010), the competition between innovative ideas within organizations has become increasingly acute as companies have introduced new platforms that enable hundreds or thousands of potential contributors to share their ideas at almost zero marginal cost. Attention is a valuable but finite resource, and the contribution that each employee can provide to each idea likely decreases when the number of ideas increases (Hansen and Haas, 2001). In addition, contributors providing suggestions on several ideas within the crowd create interdependencies and increase the degree of competitive interdependencies between ideas, thereby offering the possibility to hypothesize that the positive relationship between attention allocation and positive comments and suggestions on novel ideas posted is moderated by competition for attention. First, as the degree of competition for attention increases, contributors and evaluators are less likely to perceive competing ideas as novel (Haas et al., 2015). Moreover, higher competition for attention increases rivalry between ideators which, in turn, might reduce the likelihood that favorable feedback and comments will be provided on competing ideas (Hansen and Haas, 2001). For ideas that do not share or exhibit only a limited number of common contributors, the risk of competition for attention with other ideas is much lower. Being equal in the number

Idea survival in internal crowdsourcing

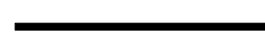


of comments received, these ideas are more likely to profit from the unique contribution of employees. On the basis of these arguments, we advance the following research hypothesis:

HP3. Competition for attention negatively moderates the relationship between idea attention and idea appreciation.

\section{Temporal distribution of ideas and idea survival}

Finally, we postulate that the survival of ideas is likely affected by the temporal distribution of idea generation during internal crowdsourcing. The literature shows that the temporal dimensions matter and can significantly affect attention allocation in organizations (Cummings and Haas, 2012). Time allocation is, indeed, of quintessential importance to explain patterns of competition as well as variation in attention dynamics where employees are allocating time to novel ideas (Palmie et al., 2015).

We assume that ideas are more likely to survive if they appear earlier and when they exhibit a longer temporal distance from other ideas posted in the jam. Having a greater exposure in the internal crowd allows ideas to attract more attention from employees (Palmie et al., 2015). This translates into increased activity around the idea and an increased likelihood for ideas to benefit from more feedback (Shapiro and Varian, 1999). Consequently, it may enhance their chances to survive and pass through the selection process internal to the organization.

This competitive process, exposed by the temporal nature of the jam, is thus extremely important (Cumming and Haas, 2012). As time elapses, the number of ideas increases. With other parameters constant, this temporal aspect modifies the individual employee's attention to the idea. This seems to be a matter of quality rather than of quantity. It cannot be completely excluded that the level of contribution or interest of individuals persists, as ideas and comments accumulate in the session. However, it appears logical that the time for individuals to contribute to ideas in a productive manner is likely to decrease as far as ideas and comments accumulate. As new ideas are created and incorporated into the ideation system, the structure of the overall attention that the organizational community allocates to ideas changes. As the session goes on, the attention of individuals is distributed among more ideas. Following this, people start to shift their interest toward a higher number of ideas. This means that any ideas posted later are less likely to receive the same attention as ideas posted earlier. Similarly, we can assume that when there is a longer time elapsed between two ideas being posted, the idea posted earlier is more likely to benefit from employees' attention.

Overall, we suggest that ideas submitted later or at a shorter distance in time from previously posted ideas are more likely to receive a lower degree of attention, thoughts, reflections and feedback. More formally, we hypothesize that:

HP4a. Ideas posted earlier in internal crowdsourcing sessions, everything else being equal, are more likely to survive.

$H P 4 b$. The likelihood of idea survival is positively related to the elapsed time between the insertion of two consecutive ideas posted in internal crowdsourcing sessions.

Figure 1 illustrates our research model and the relationships between the hypotheses.

We now turn to a presentation of the research methods used to test the hypotheses presented above, starting with a description of the research setting and the data collection in the study.

\section{Research methodology}

Research setting and data collection

A business unit within a large global manufacturing company based in Sweden was selected in order to test our research hypotheses. The company is within the transportation industry. 


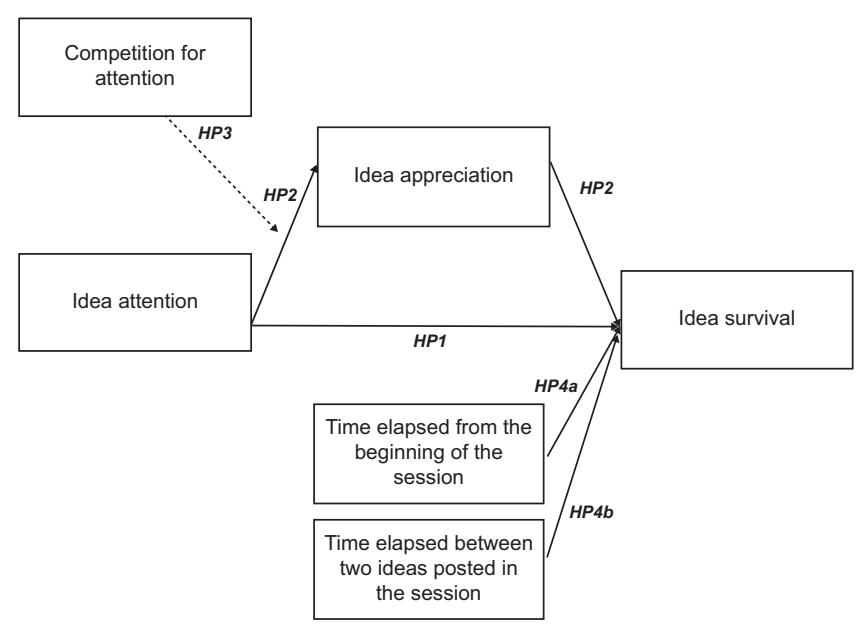

Idea survival in internal crowdsourcing

The selected business unit is research-focused and supports the other business areas and units of the global company in their innovation efforts. One of its specific activities is to run ideation jams, which are IT-mediated crowdsourcing sessions in which employees are invited to contribute with ideas and comments on ideas recorded within a set time frame (normally $48 \mathrm{~h}$ ). An ideation jam is preceded by a period of marketing initiatives in which employees receive links via email to web pages on the company intranet with inspiration and stimulation related to the subject of the jam. These inspiration sessions may, for instance, present a specific customer profile, the needs of which are presently not met by the organization. Another example could be the highlighting of specific environmental problems within the organization that require tailored solutions. During a jam, employees can contribute with both their own ideas and comments on others' ideas. After a jam has been concluded, a number of specific ideas are selected for implementation in innovation projects.

For the present study, one specific jam was selected. This jam was open for employees from the whole company to contribute to. Real data on all ideas submitted, their related comments, and the employees who contributed were extracted from the company's internal data system. In addition, one interview with the manager responsible for the business unit and two interviews with the person in charge of running the internal crowdsourcing sessions were conducted. The interviews lasted $1.5-2 \mathrm{~h}$ each and added to the understanding of how the jam was carried out, as well as how the evaluation and selection processes were performed. In addition, thanks to already established contacts between the researchers and the company, going back years, it was possible to easily clarify any remaining questions about the jam. The exact nature of the ideas cannot be presented here, as they remain commercially confidential. The jam was ordered by a group function in the company dedicated to business innovation. The steering group of people involved in deciding the jam was from corporate strategy, a venture capital unit within the company, and a "specific issue board" focusing on soft products, i.e. service offers connected to the company's products. The director responsible for innovation was the leader of the steering group. This group both set the scope of the jam and made the final decisions on the ideas generated. The selected jam spanned a number of different expertise and knowledge domains and was active for a period of $48 \mathrm{~h}$. During this session, ideas were created and developed by a large number of employees, something which can be regarded as a live experiment emulating what normally occurs in organizations, although in a much more compressed time-frame and supported by IT. Ideas generated in the jam were evaluated and presented anonymously. Of course, there was a 
possibility to check who had contributed to an idea in a particular way, but for the company it was important that the focus was kept on the ideas and that everyone could contribute to their development. This meant that the selection of ideas to be further developed in projects was based solely on the ideas and their development in the comments, and not on the individuals behind them; this was also clearly communicated to participants before the jam. The rationale for this was that the ideas were not to be seen as owned by one creator after they were posted, but everyone could contribute to the idea, and collaborative actions leading to new ideas were promoted. The jam was supervised by a number of moderators, selected based on their expertise. Overall, the creative jam analyzed in this paper originally contained 351 ideas and 1,092 comments posted by 224 employees. Ideas were posted on such topics as on new business, new efficient and effective transportation solutions, or new services to offer customers.

Patterns of attention allocation were represented using a matrix composed of employee-idea dyads, in which the $i j$ th cell is 1 if employee $i$ provided an idea or comment on idea $j$ or 0 if employee $i$ did not provide any idea or comment on idea $j$ (Björk and Magnusson, 2009; Björk et al., 2011; Haas et al., 2015). The contributors in these dyads included all individuals posting at least one idea. In the present study, we were also interested in understanding the nature of comments provided on single ideas. Two independent coders read and analyzed all comments provided in the jam. All comments were coded according to whether they were positive, negative or neutral about ideas. The analysis of inter-rater reliability showed a high level of agreement ( $>95$ percent). In cases of disagreement, the two raters reviewed their analysis and reached a consensus. For some ideas, we were unable to access comment data. The final dataset used in our analyses therefore contains 280 ideas (and 866 comments) posted by 137 individuals.

\section{Variables and measures}

Idea survival. The main dependent variable used in this paper is idea survival measured as a dichotomous variable with 1 indicating idea survival, i.e. selection and transformation into a formal organizational project for further development, and 0 indicating idea rejection (Schemmann et al., 2016). The evaluation of ideas posted in the innovation system was performed stepwise. In sequence, the individual moderators, then the innovation group, and finally the steering group evaluated all ideas. The whole evaluation was not to take longer than a month and in particular the first step of the evaluation had to be done in two days. Each moderator first compiled a list of the three to ten ideas that he/she found most promising. This initial step was performed with the occasional help of subject-matter experts and with continuous coaching from the innovation group. The moderators then independently evaluated all ideas found to be promising and rated them on a scale (low-high), considering possible impacts and risks for the proposed commercial product/service. Thereafter, the innovation group, with the help of experts, again evaluated the ideas, merged similar or complementary ideas, and then transferred a final list of all remaining ideas to the steering group. The steering group then made the final selection of ideas to be turned into innovation projects, each of which was endowed with a budget of 200kSEK to further develop its technological and business aspects.

Idea attention. Measures the total number of comments received by each idea posted in the jam (Schemmann et al., 2016). This variable seems particularly suitable to capture the overall attention that the idea has created around itself and the amount of energy and activity it has generated.

Idea appreciation. Measured as the number of positive comments that contributors posted on ideas submitted in the innovation system (e.g. Schemmann et al., 2016), we hypothesized this variable as having a mediating role between idea attention and the likelihood of idea survival.

Competition for attention. Represents the overall level of interdependencies that exists between ideas, as expressed by the extent of overlap in patterns of attention allocation in the 
ideation session. Attention overlap between ideas was derived from the concept of niche overlap. According to the organizational population ecology paradigm, niches represent spaces of resources that are vital for the survival of a given organizational population and niche overlap is viewed as a predictor of the existing competitive aggressiveness between organizations (Hannan and Freeman, 1989). Similarly to other measures developed previously for the computation of niche overlap, attention overlap in the present study was expressed through a measure of crowdedness (Podolny et al., 1996; Hansen and Haas, 2001). A rectangular array of dimension " $n \times m$ " was built as a starting point, where rows contained ideas and columns contain contributors to ideas. Each cell contained the number of suggestions that a given employee provided to one of the ideas posted in the jam. Row vectors represented the aggregate number of comments single ideas received from the various employees. The overlap or "intersection" between pairs of ideas could then be calculated by comparing vectors for the level of similarity with regard to patterns of attention that employees allocated through their suggestions. To increase the accuracy of the calculation overlap, attributive data on individual employees were used to distinguish between the different business areas of the company to which they belonged. This allowed to take into account the potential content of suggestions provided by the different employees on any particular idea. For each business area, dyadic attention overlap was finally computed as: $a_{i j}=\sum_{1}^{k} c_{i j k} / \sum_{1}^{k} s_{i k}$. Here, $c_{i j k}$ indicates the smaller of the number of suggestions that an employee $k$ provides to both idea $i$ and idea $j$; the weight $s_{i k}$ indicates the proportion of suggestions that idea $i$ receives from employee $k$; the numerator expresses the overall sum of overlaps between ideas $i$ and $j$ across all contributors; the denominator indicates the total attention (i.e. total number of comments) that employees allocate to idea $i$. The attention overlap coefficient $\alpha_{i j}$ is then interpreted as the proportion of overlap between suggestions that two ideas receive. For a given idea, the sum of dyadic attention overlap coefficients measured the extent to which one idea overlaps for cognitive resources with all other ideas posted and discussed in the innovation session. To arrive at a global measure of crowdedness for idea $i$, the dyadic attention overlap measures were summed in the following manner: $\alpha_{i}=\sum_{j \neq i}^{N} \alpha_{i j}$.

Time lag since start of session. It is measured as the natural logarithm of minutes that elapsed between the beginning of the crowdsourcing session and insertion of the idea.

Time lag since previous idea. This variable indicates the time (expressed in minutes) elapsed between the insertion of two consecutive ideas.

Several control variables were introduced in order to capture other factors that could potentially explain the appreciation and selection of ideas. These variables concern both ideas entering the session and individual contributors.

Idea description length. Previous studies show that the number of words used to express an idea may affect the likelihood of idea selection in internal crowdsourcing sessions (e.g. O'Leary, 2016). For this reason, we controlled for Idea description length, measured as (the natural logarithm of) the number of characters used to describe the ideas posted.

Attachments. Some crowdsourcing sessions - such as the one explored in the present study - offer the possibility to include attachments to posted ideas. We thus included a binary variable termed Attachments to capture whether any external link was present in the description of posted ideas.

Average length of comments. Because the number of words in the comments may also be related to idea selection (e.g. O'Leary, 2016), we included the variable Average length of comments, measured as (the natural logarithm of) the average number of characters in comments that ideas received.

Negative comments. In internal crowdsourcing, contributors may also express negative sentiments toward ideas, which likely influence idea selection (O'Leary, 2016). We controlled 
for the number of Negative comments to test whether criticisms of or negative reactions to posted ideas may affect idea survival.

Ideators' self-comments. Finally, we controlled for the number of Ideators' self-comments because we believe that comments provided by ideators on their own ideas may affect the relevance and salience that ideas assume for other contributors.

A further three control variables concern ideators' characteristics:

Ideators' activity. This variable was employed to account for the possibility that ideas posted by individuals providing more comments are more likely to be implemented (Schemmann et al., 2016). This variable was computed as the (natural logarithm of the) total number of comments posted by each contributor.

Manager. Since we believe that holding a managerial position in the organization implies the possibility to direct and receive more comments, as well as to influence indirectly the likelihood of an idea to be selected, we included a variable labeled Manager taking on 1 when the idea originates from somebody with managerial responsibilities and 0 for otherwise.

Gender. Finally, we controlled for Gender of the ideators since this may affect the quality of posted ideas (Zhu et al., 2017). This is a binary variable that takes 1 for male and 0 for female.

\section{Statistical analysis}

Because ideas posted to the online innovation system were partially nested within individuals (i.e. the same individual may post multiple ideas), we used multilevel modeling to address the issue of potential non-independence of the observations. We conducted the analyses by using multilevel mixed-effects Poisson regression (Rabe-Hesketh and Skrondal, 2008) to estimate idea appreciation, and multilevel mixed-effects Logistic regression ( $\mathrm{Ng}$ et al., 2006) to estimate the likelihood of idea selection.

We developed four different regression models to test our research hypotheses. The first three models were developed to test our hypotheses HP1 and HP2, following Baron and Kenny's (1986) procedure. In particular, Model 1 tests the relationship between idea attention, i.e. the total number of comments, and idea appreciation, i.e. the number of positive comments received by ideas. Model 2 tests the relationship between idea attention and idea survival, as hypothesized in HP1. Model 3 tests the impact of both idea attention and idea appreciation on idea survival. According to Baron and Kenney (1986), idea appreciation is a mediator as hypothesized in our HP2 if (1) idea attention significantly predicts idea appreciation in Model 1; (2) idea attention significantly predicts idea survival in Model 2; and (3) coefficients for the idea attention variable that are significant in Models 1 and 2 either become insignificant or at least decrease in their significance in Model 3.

A final model, termed Model 4, includes the interaction effect aimed at testing our prediction that competition for attention negatively moderates the positive relationship between idea attention and idea appreciation. We ran all analyses by using mixed modeling procedures as implemented in Stata 13.

\section{Results}

Table I reports descriptive statistics and correlation coefficients for all variables used in the study. We first checked the correlations among all independent and control variables and found no evidence of multicollinearity. The highest correlations are between Idea attention and Competition for attention $(0.84, p<0.05)$, Competition for attention and Ideator's self-comments $(0.76, p<0.05)$, and Idea attention and Ideator's self-comments $(0.61, p<0.05)$. Also, the variance inflation factors (VIFs) are below the recommended threshold of 10 . 


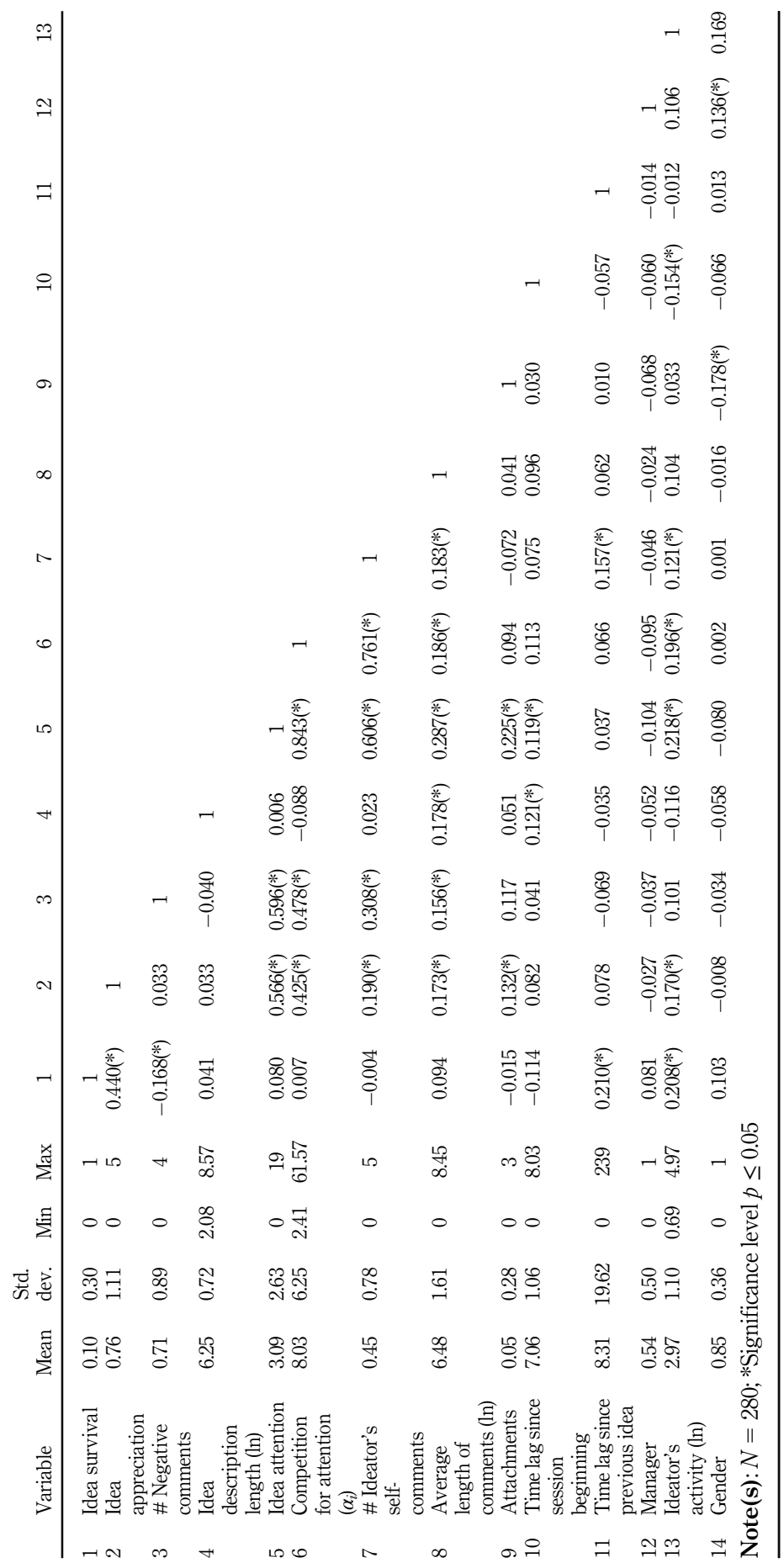

Idea survival in internal crowdsourcing 
Overall, 280 ideas were investigated, from which 27 survived to go through the internal assessment process. Selected ideas received a total of 101 comments, averaging four comments per idea, and 61 positive comments, with an average of 2.26 positive comments per idea. The number of comments for ideas not withheld was 765, averaging 3 comments per idea. For these ideas, 153 positive comments were provided, with an average of 0.6 positive comments per each posted idea. As for contributors, 137 employees participated in the ideation jam by contributing at least once to the ideas. Out of all the contributors, 74 employees held a managerial position ( $\sim 54$ percent), and 63 were employees without a managerial position. Twenty-one female employees ( 15 percent) took part in the jam.

Figure 2 illustrates the temporal dynamics of the overall distribution during the 48 -h period, with those ideas selected distinguished from the others. The graphs representing the patterns of the number of comments over time are described in Figure 3. Figure 4 describes patterns of positive, negative and neutral comments provided for all ideas posted in the online system over time.

As Figure 2 shows, ideas are uniformly distributed throughout the jam session. However, a decreasing number of ideas gets selected as time elapses. The number of comments posted appears to follow a wave-like pattern with three peaks achieved shortly after the start (after $8 \mathrm{~h}$ ), between the 24th and 32nd h, and in the last three hours of the session. Figure 4 shows that the number of positive comments sometimes outreaches that of negative and neutral comments, specifically between the 7th and 11th h, and then around the 34th and 40th $\mathrm{h}$.

Table II presents the results of the regression analyses. From the null model, we observe that 13 percent of the variance in idea survival was attributable to individuals. Although not quite high, this value is above the 10 percent worth consideration level (Hayes, 2006). In Table II, Model 1 shows that the variable Idea appreciation is positively and significantly related to Idea attention $(\beta=0.294 ; \mathrm{IRR}=1.34 ; p<0.01)$, indicating that the higher the number of comments received by a given idea, the more likely the idea was to be positively evaluated by the online system participants. This result confirms our first research hypothesis and overall corroborates previously reported findings on ideation in internal crowds (Di Gangi and Wasko, 2009; Reitzig and Sorenson, 2013; Schemmann et al., 2016). Model 2 shows that Idea survival is predicted by Idea attention ( $\beta=0.701$; $\mathrm{OR}=2.01 ; p<0.05)$, thus supporting our hypothesis HP1. However, in Model 3 which aims at verifying the mediation effect of Idea appreciation, we observe that while Idea survival is significantly related to Idea appreciation $(\beta=1.810 ; \mathrm{OR}=6.11 ; p<0.01)$, it is no longer related to the variable Idea attention[1]. Overall, these findings indicate that Idea appreciation mediates the positive relationship between Idea survival and Idea attention, hence supporting our hypothesis HP2.

Model 4 includes the interaction variable Idea attention $\times$ Competition for attention in order to test our hypothesis HP3. The coefficient of this variable is negative and significant $(\beta=-0.004 ; \mathrm{IRR}=0.99 ; p<0.01)$, indicating that overlaps in patterns of attention allocation matter. Specifically, this result demonstrates that the positive relationship between idea attention and idea appreciation decreases as far as competition for attention increases. Figure 5 illustrates the moderation effect.

Model 3 in Table II incorporates the variables Time lag since start of session and Time lag since previous idea to test our research hypotheses HP4a and HP4b. The parameter for Time lag since start of session is negatively and significantly associated with idea survival $(\beta=-0.714$; $\mathrm{OR}=0.49 ; p<0.05)$, indicating that ideas posted early in the ideation jam were more likely to survive. As time passes, ideas accumulate in the jam, and this generates competition amongst ideas. Patterns of attention and feedback toward ideas change in this situation because employees start contributing to more ideas at the same time. As ideas accumulate in the jam, they are less likely to attract the attention of contributors, who have fewer cognitive resources to dedicate to more recently posted ideas. The variable Time lag since previous idea is instead positively associated, although with only marginal significance, to the likelihood of idea selection 


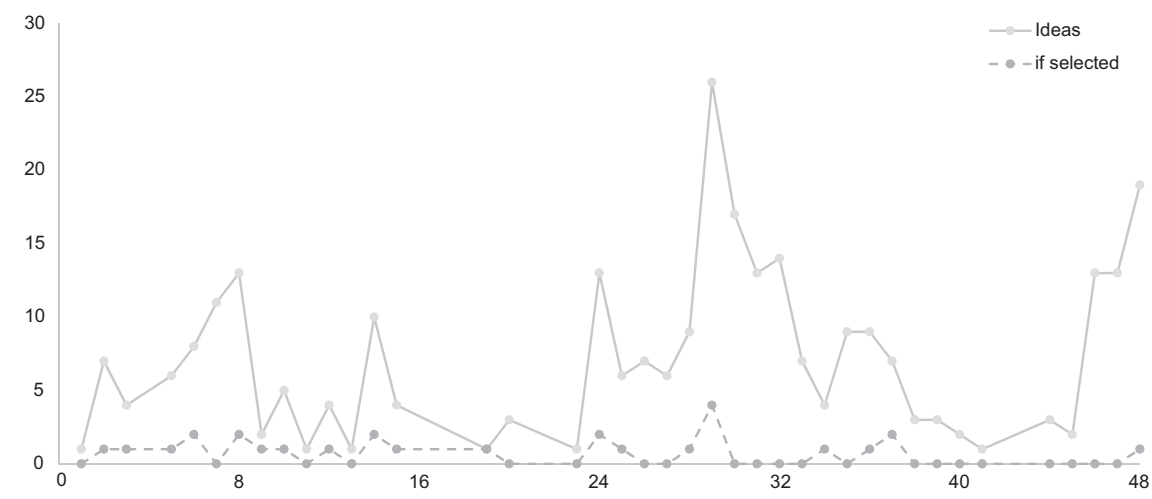

Idea survival in internal crowdsourcing

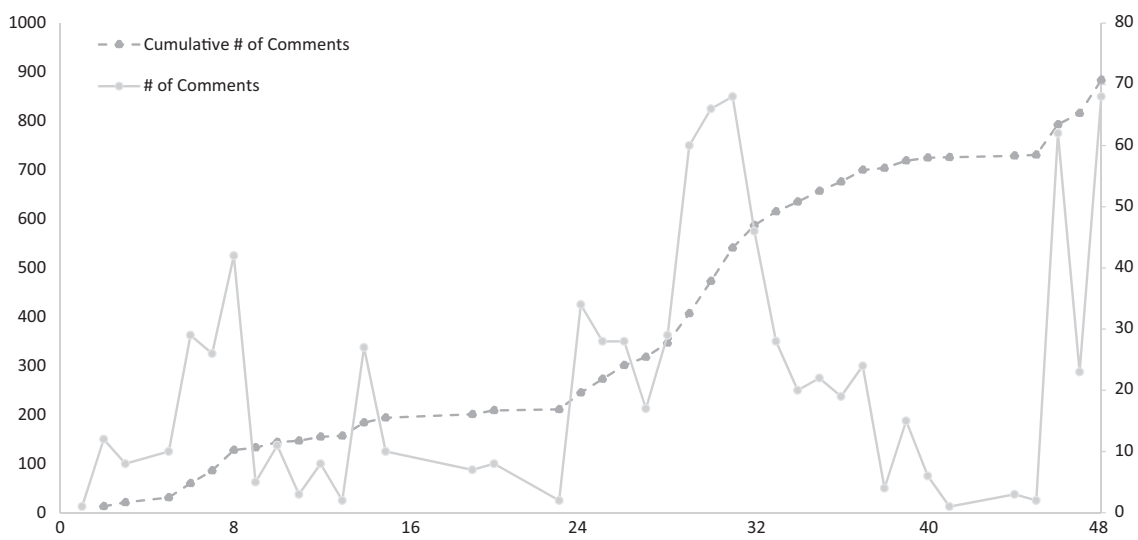

Figure 3.

Patterns of the number of comments over time (48 h)

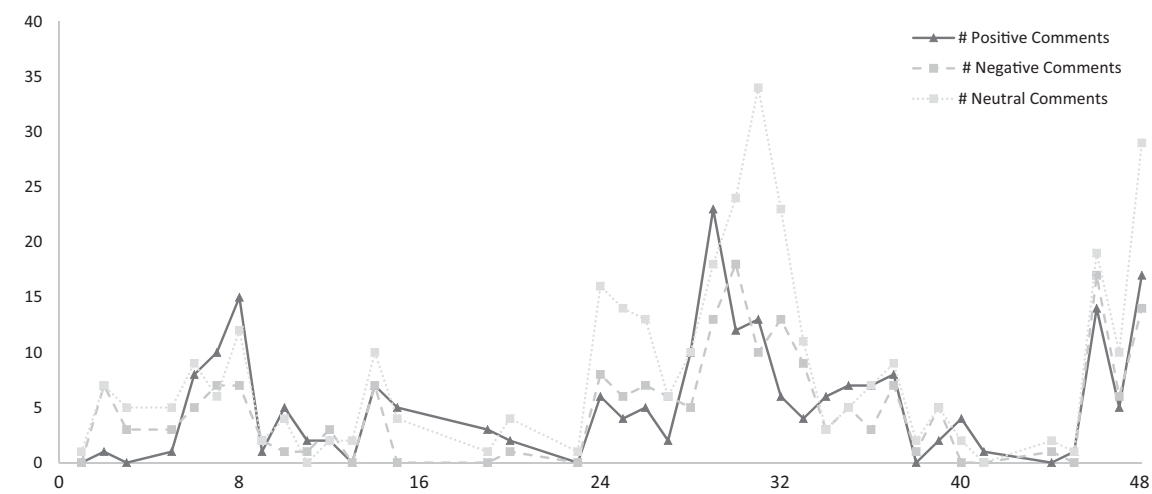

Figure 4.

Patterns of the positive, negative and neutral comments over time $(48 \mathrm{~h})$

$(\beta=0.037 ; \mathrm{OR}=1.04 ; p<0.1)$. This suggests that a positive assessment of ideas is more likely to occur when the moderator and other actors involved in the evaluation process see that ideas have been sufficiently exposed to the criticisms of participants, giving them adequate time to react and provide suggestions. Overall, this confirms our hypotheses HP4a and HP4b. 
EJIM

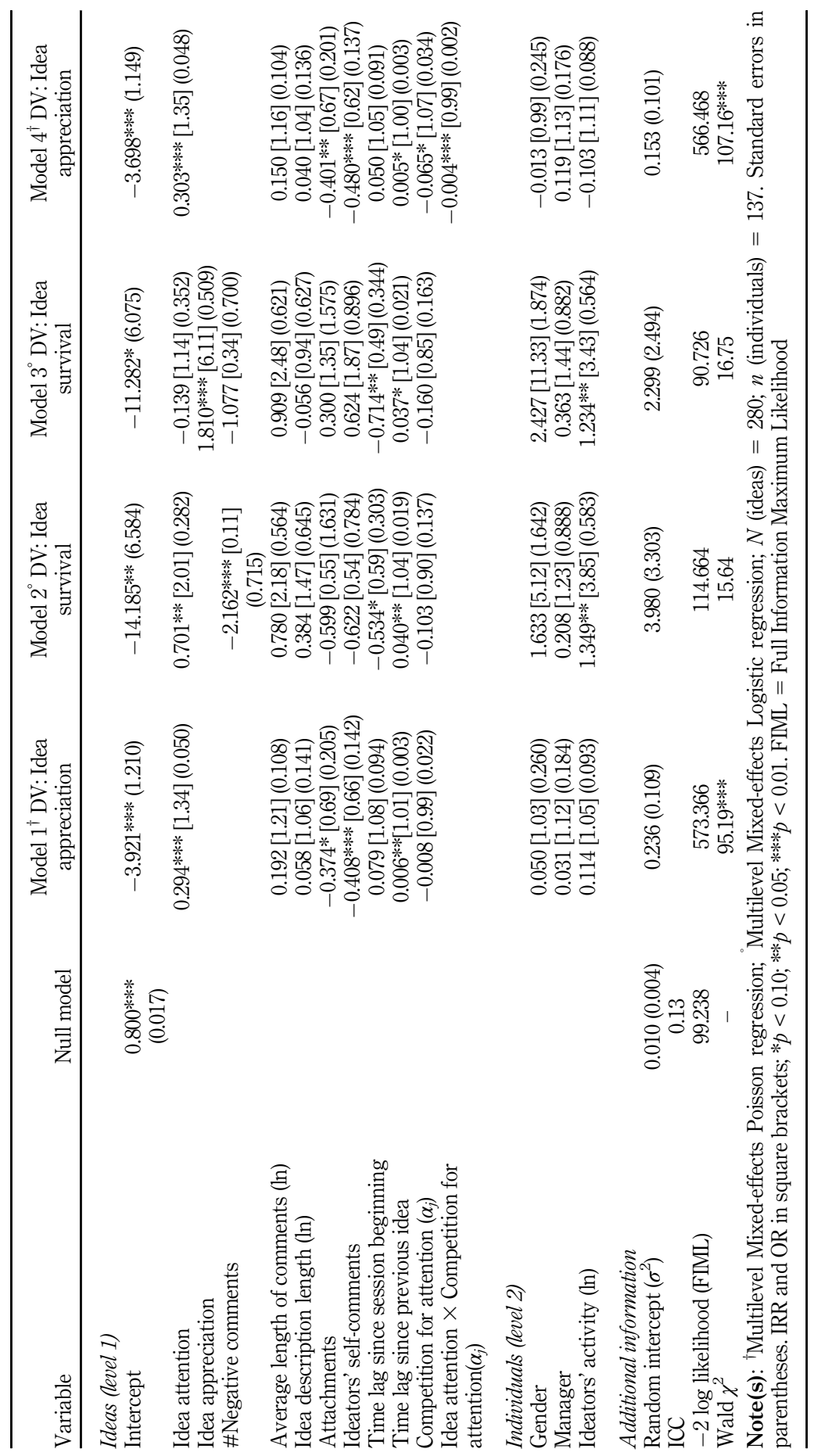

Table II. effects regression results 
The results shown in Table II show that some of the control variables included are significant. First, the negative parameter for the variable Attachments indicates that ideas are less likely to receive positive comments if they include attachments. This counterintuitive result seems to suggest that employees are constrained by the time allotted to participate in the online session, such that they negatively assess those ideas that invite participants to refer to external links for more details. The lack of significance of variables Idea description length and Average length of comments in all models seems to corroborate this intriguing result. Furthermore, the negative parameter for Ideas' self-comments indicates that participants do not judge positively the ideas inflated by a high number of self-comments. Finally, among the control variables at individual level, Ideator's activity is significantly associated with idea selection. Specifically, the positive parameter of variable Ideator's activity in Models 2 and 3 indicates that ideas are more likely to be selected when posted by more active employees.

Table III provides a summary of the obtained results along with evidence for the proposed research hypotheses.

\section{Discussion}

As presented earlier, the empirical results offer support for all the proposed hypotheses. The analysis first of all corroborates that idea attention is positively related to idea survival in internal crowdsourcing. Malhotra and Majchrzak (2014) have argued that attention given to ideas helps them surface in the ideation process, thus increasing their likelihood to be selected for further development and implementation. Our results support this inter-relationship, even though they do not inform us about the direction of causality, and it could also be the case that attention to ideas is a result of their apparent quality, as indicated by Reitzig and Sorenson (2013). Moreover, the results in this study offer additional insights into the relationship between idea attention and idea survival, by also including the mediating effect of idea appreciation. Positive feedback on an idea may increase its legitimacy in the eyes of other organizational members (Di Gangi and Wasko, 2009) and thereby increase its survival probability. The results support this interpretation, as it is found that the appreciation of an idea, which to some extent is driven by the amount of attention given to it, in turn increases its probability for survival.

Also when it comes to the hypothesized effects of competition, the performed study offers empirical support. With increasing competition between ideas, the link between attention and idea survival is weakened. Our investigation does not allow us to observe whether this is a result of less commenting per idea when there are more competing ideas, or a result of fewer

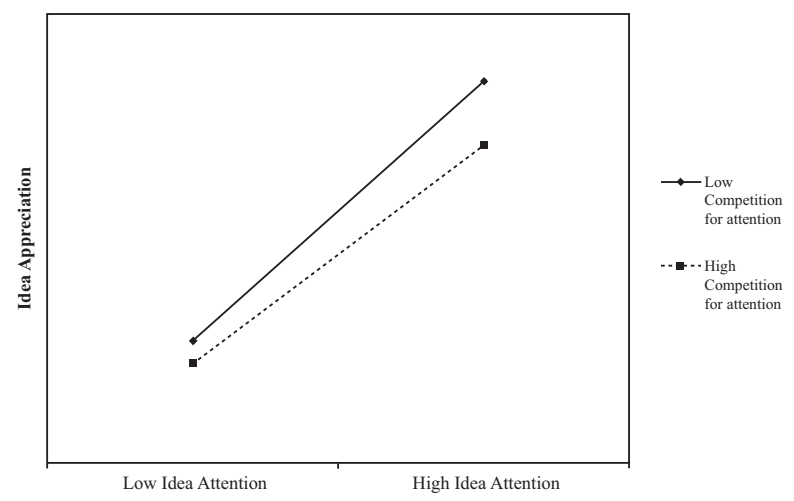
Idea survival in
internal
crowdsourcing

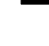




\section{EJIM}

\begin{tabular}{|c|c|c|c|}
\hline Hypothesis & Formulation & $\begin{array}{l}\text { Obtained results (estimated } \\
\text { parameters/regression model) }\end{array}$ & Confirmation \\
\hline & $\begin{array}{l}\text { Idea attention is positively related to } \\
\text { idea survival in internal } \\
\text { crowdsourcing }\end{array}$ & $\left(\beta_{\text {IdeaAttention }}=0.701 ; p<0.05\right) /$ Model 2 & Yes \\
\hline P2 & $\begin{array}{l}\text { Idea appreciation mediates the } \\
\text { relationship between idea attention } \\
\text { and idea survival }\end{array}$ & $\begin{array}{c}\left(\beta_{\text {IdeaAttention }}=0.294 ; p<0.01\right) / \text { Model } 1 \\
\text { and }\left(\beta_{\text {IdeaAppreciation }}=1.810 ; p<0.01\right) / \\
\text { Model } 3\end{array}$ & Yes \\
\hline & $\begin{array}{l}\text { Competition for attention negatively } \\
\text { moderates the relationship between } \\
\text { idea attention and idea appreciation }\end{array}$ & $\begin{array}{c}\left(\beta_{\text {IdeaAttention } x \text { CompetitionAttention }}=-\right. \\
0.004 ; p<0.01) / \text { Model } 4\end{array}$ & Yes \\
\hline $4 \mathrm{a}$ & $\begin{array}{l}\text { Ideas posted earlier in internal } \\
\text { crowdsourcing sessions, everything } \\
\text { else being equal, are more likely to } \\
\text { survive }\end{array}$ & $\begin{array}{c}\left(\beta_{\text {TimeSessionBeginning }}=-0.714\right. \\
\quad p<0.05) / \text { Model } 3\end{array}$ & Yes \\
\hline $\mathrm{P} 4 \mathrm{~b}$ & $\begin{array}{l}\text { The likelihood of idea survival is } \\
\text { positively related to the elapsed time } \\
\text { between the insertion of two } \\
\text { consecutive ideas posted in internal } \\
\text { crowdsourcing sessions }\end{array}$ & $\begin{aligned} &\left(\beta_{\text {TimePreviousIdea }}=\right.0.037 ; p<0.1) / \text { Model } \\
& 3\end{aligned}$ & Yes \\
\hline
\end{tabular}

positive comments from the providers of competing ideas (Hansen and Haas, 2001), but nevertheless underlines that an overload of attention in ideation processes may introduce a bias in the selection of ideas. This finding adds to previous results, highlighting the need to consider both the scale and the transparency used in internal crowdsourcing activities. Whereas an increased number of contributors in crowdsourcing logically increases the probability that a number of the generated ideas are sufficiently novel, valuable and useable to motivate their realization into innovations, the resulting competition for attention between numerous ideas may render the identification of promising innovation ideas more challenging. Furthermore, it is noted that the use of transparent internal crowdsourcing processes allows for improvements of ideas through the commenting by other contributors (Chen et al., 2020), the transparency also brings about competition for attention, which may lead to difficulties to correctly identify the most promising innovation ideas.

Finally, the analysis offers new insights regarding the effects of timing in ideation processes. Recent studies on ideation (Chen et al., 2020; Palmie et al., 2015) have suggested that idea success depends on exposure. Increased exposure can result from increased attention when an idea does not surface at the same time as other ideas. We contribute to this literature by also finding that ideas emerging earlier in the ideation processes have a higher probability for survival. By arriving before potentially competing ideas, an idea has a higher possibility to gain legitimacy stemming from the attention it receives, thereby making it harder for similar ideas that are proposed at a later stage to become the preferred ones.

Organizations are increasingly taking on the challenge to foster ideation and innovation within their boundaries by implementing new, and to a large extent emergent and self-organized systems aimed at tapping into the internal creative potential of their employees (Malhotra et al., 2017; Bayus, 2013; Jeppesen and Lakhani, 2010; Bjelland and Wood,2008). Having good ideas is of course of fundamental importance. However, facilitating comments and constructive feedback on the ideas generated is also important, both in order to further develop proposed ideas and in order to give correct priority to those opportunities for which organizations have resources to develop further (e.g. Zhu et al., 2017; Shemmann et al., 2016). The present study has explored, for the first time, the dynamics of comments and feedback generated in a 48-h IT-based internal crowdsourcing session, and in so doing contributes to the existing literature on internal 
crowdsourcing. While previous research on this topic has widely recognized the general contribution of employees to the ideation process within organizations (Beretta, 2019; Malhotra et al., 2017), the present study represents a first attempt to investigate how employees contribute to idea development in a highly compressed timeframe. Attention-based theory emphasizes that attention is a scarce resource and focuses on factors that explain how workers allocate their attention toward certain targets (Ocasio, 2011; Dahlander and Piezunka, 2014). The 48-h crowdsourcing session affords the analysis of how employees' attention, here expressed in the form of suggestions and comments, is allocated to certain ideas rather than others. This study reconciles crowdsourcing research and attention theory, exploring how the interaction between employees and ideas leads to the formation of emergent patterns of attention allocation, thereby explaining how ideas develop in the crowd. In the particular context investigated, the internal crowdsourcing session was created to increase interaction and communication among the employees. Patterns of comments on all ideas generated were explored in order to reveal how employees spontaneously choose to allocate their attention to ideas. This resulted in the formulation of a social structure representing relations between all the crowd members and all the ideas submitted and commented upon. Consistently with recent studies (Haas et al., 2015), we assumed that the attention, interest and subsequent contributions to ideas provided by employees are fundamental resources for which ideas strive and compete. The social structure thus constructed predicted some characteristics of cognitive dynamics, which in turn influenced the likelihood of idea survival. The present findings expand prior knowledge concerning the organization of internal crowdsourcing for ideas (Chen et al., 2020; Malhotra et al., 2017; O'Leary 2016; Malhotra and Majchrzak, 2014; Majchrzak and Malhotra, 2013; Bjelland and Wood, 2008). First, the results show that idea appreciation mediates the impact that idea allocation has on idea survival. We also observe that complex competitive interdependencies emerge in internal crowdsourcing sessions whenever employees provide comments on generated ideas. Research has viewed this as a clear signal of collaboration, but also as a sign of competition among people and their knowledge (Hansen and Haas, 2001). In the present study, it was postulated that competition arises between ideas when they share common third individuals who start commenting on two or more somewhat related ideas, leading to attention overlap. This phenomenon affects the overall likelihood of ideas to be appreciated and, therefore, go through the internal innovation process.

An additional contribution is provided by the investigation of the timing of idea submission in the crowdsourcing session. The point in time when ideas are posted into the crowdsourcing session likely affects employees' attention allocation, which in turn is highly important for idea survival.

The richness and diversity of information, attention, and decision-making research points to the promise of this burgeoning field of inquiry, but also poses a clear challenge to research in management. Given the decreasing quantity of attention available to be allocated to any given piece of information, a useful direction for future research would be to explore how and when to structure environments in which the quality of attention allocated to a given task is as high as possible, even if the attention quantity is not great. In addition, it is becoming increasingly important to consider how we can understand and capture the quality, and not only the quantity, of attention that individuals are able to allocate to their tasks under varying conditions (Van Knippenberg et al., 2015). Moreover, ideas that receive many appreciative comments then become more well-known in the organization and therefore might have advantages in the later development stages in terms of already gained legitimacy within the organization, something that is of great interest to understand how ideas develop to innovation in organizations (see, e.g. Bunduchi, 2017).

Taken together, the findings of this study highlight some patterns likely to result from crowdbased behaviors, where other members of the crowd influence individuals, with some similarity to collective behaviors displayed by other complex adaptive systems (Gloor, 2017). By pointing 
out these patterns, this article also underlines the necessity of carefully considering the limitations to individual rationality imposed by a specific social context such as an internal crowdsourcing session, as well as its effects on idea generation, development and selection. Hence, there is a need to first of all carefully distinguish between different types of crowdsourcing approaches, in terms of their interaction structures. The earliest forms of crowdsourcing focused primarily on communication from numerous individuals to a problem owner. Irrespective of whether this problem owner was primarily aiming to benefit from the statistical power of large numbers or the access to an individual expert providing a specific solution, community-like interaction between members of the crowd was not sought after. With the development of more sophisticated virtual interaction platforms, many organizations have embraced a more collective approach to ideation, often putting great emphasis on the possibilities of individuals to support and help each other to jointly generate and develop fruitful innovation ideas. It is obvious that such collective creativity holds significant potential, but its potential downside has not been thoroughly investigated. The present study addresses this specific issue, by making explicit how attention in a social context such as an internal crowdsourcing session may influence individual attention and as a consequence bias the survival of ideas. The effects of this can be both that good ideas are incorrectly discarded due to a lack of attention, leading ultimately to missed innovation opportunities, and high levels of attention leading to incorrect investment in bad innovation ideas. The solution to this potential issue is hardly to discard crowdsourcing and replace it with more traditional ideation approaches, but rather to find out if there are ways of avoiding systematic biases and thus achieve an idea selection that is as rational and unbiased as possible.

\section{Managerial and practical implications}

The present results have important managerial and practical implications. First, this study provides the organizers of internal crowdsourcing sessions with new insights about factors influencing idea survival. The finding that idea attention influences idea survival, and that this relationship is mediated by idea appreciation, points to the possibility to simplify the idea selection process by analyzing the commenting behavior of the crowd. Hence providing the possibility to get a quick view of which ideas might be subject to selection even before a formal evaluation process. However, as there are many aspects of ideas that need to be considered during their evaluation, and it cannot be guaranteed that crowd members actually attend to all of these, the information from the crowd should most likely be used merely as a complement to other types of evaluation. However, used in such a manner, information commenting behavior could be used to improve the idea selection process.

Second, the results provide insights about potential systematic biases in idea selection due to timing and competition between ideas. Competition between ideas reduces the mediating effect of idea appreciation. This points to the difficulty of relying on positive comments when similar ideas are to be evaluated, as the commenting behavior may then depend on individuals' relationships to particular ideas, rather than objective evaluations. Even more important, in terms of its practical implications, is the finding that timing influences idea survival. The time available to attend to an idea actually influences the resulting attention, and this highlights the problem of not giving ideas equal opportunities to be selected as they show up at different stages of a crowdsourcing session. This can be handled by dividing the crowdsourcing session into more specific stages or steps. By having a first stage, which exclusively focuses on idea generation - without commenting - and then following this up with an interactive stage for commenting where all ideas are presented at the outset, the problem of timing could be avoided. Even if this implies a more structured process, it is difficult to see that this increased linearity of the process would actually hamper the creativity of crowd members.

Internal crowdsourcing often constitutes online brainstorming sessions, and even with participants from different locations of the company around the world, these sessions should be 
managed so as to take advantage of many of the strengths of traditional brainstorming sessions where people can suggest their ideas freely. Because of its online format, the crowdsourcing could, however, also present many difficulties common to large brainstorming sessions. One example of such a difficulty is that many ideas can be completely alien to the organization's businesses. This problem can most likely be reduced by defining the scope of the crowdsourcing session carefully and by making explicit what kind of ideas the company is looking for. In addition, given the limited time available, the commenting could be more difficult in crowdsourcing than in traditional brainstorming sessions, with a great loss of time on the part of the ideators in responding to comments of any kind.

\section{Limitations and directions for future research}

The present findings should be interpreted in the light of some important limitations, each indicating clear directions for future research. First, the research only considered a single internal crowdsourcing session performed during a limited time period. Future studies may include more sessions and/or sessions of a longer duration to produce more robust results. Second, like all individual case study, there are context-related idiosyncrasies that pose problems of generalization outside and/or in other settings. Despite these, however, we believe that the issues addressed remain of general interest and relevance for innovation and ideation management studies. Future studies should address the applicability of the present results in different contexts and in different industries. Third, the selection of ideas does not necessarily reflect their objective quality. In the present study, we measure idea appreciation but we do not have at our disposal evidence regarding the quality of selected ideas, as reflected in subsequent innovation performance. Future studies should elucidate to what extent selection of ideas actually corresponds to either superior quality or impact. Finally, even though a number of control variables were included to better control the attribution of significant effects, still other, as yet unexplored factors may help to disentangle and understand the reasons underlying the selection of ideas in an even better way. For instance, variables taking into account how ideators share ideas with people (i.e. customers or stakeholders) outside the organization could be used.

Despite these limitations, the presented results provide novel insights into the functioning of internal crowdsourcing and how different factors related to human attention influence the survival of ideas during this type of creative session, and highlight a nascent research avenue with diverse further development opportunities.

\section{Note}

1. The appearance of considerable mediation was confirmed when we performed the Sobel test (Baron and Kenney, 1986), which provides a direct test of the indirect effect of an independent variable on the dependent variable through the mediator (Sobel, 1982). We calculated the test by using the bootstrapping approach (Shrout and Bolger, 2002). The value of this statistic was $0.06(p<0.05 ; 95 \%$ CI: 0.03-10), providing full support for our hypothesis HP2.

\section{References}

Afuah, A. and Tucci, C. (2012), "Crowdsourcing as solution to distant search", Academy of Management Review, Vol. 37 No. 1, pp. 355-375.

Amabile, T. (1996), Creativity in Context, Westview Press, New York.

Baron, R.M. and Kenny, D.A. (1986), "The moderator-mediator variable distinction in social psychological research: conceptual, strategic, and statistical considerations", Journal of Personality and Social Psychology, Vol. 51 No. 6, pp. 1173-1182. 
Bayus, B.L. (2013), "Crowdsourcing new product ideas over time: an analysis of the Dell IdeaStorm community", Management Science, Vol. 59 No. 1, pp. 226-244.

Benbya, H. and Van Alstyne, M.W., (2010), "How to find answers within your company", MIT Sloan Management Review, Vol. 52 No. 2, pp. 66-77.

Beretta, M. (2019), "Idea selection in web-enabled ideation systems", Journal of Product Innovation Management, Vol. 36 No. 3, pp. 5-23.

Bjellan, O.M. and Wood, R.C. (2008), "An inside view of IBM's Innovation Jam”, MIT Sloan Management Review, Vol. 50 No. 1, pp. 32-40.

Björk, J. and Magnusson, M. (2009), "Where do good innovation ideas come from? Exploring the influence of network connectivity on innovation idea quality", Journal of Product Innovation Management, Vol. 26 No. 6, pp. 662-670.

Björk, J., Di Vincenzo, F., Magnusson, M. and Mascia, D. (2011), "The impact of social capital on ideation", Industry and Innovation, Vol. 18 No. 6, pp. 631-647.

Bogers, M., Zobel, A., Afuah, A., Almirall, E., Brunswicker, S., Dahlander, L., Frederiksen, L., Gawer, A., Gruber, M., Haefliger, S., Hagedoorn, J., Hilgers, D., Laursen, K., Magnusson, M., Majchrzak, A., McCarthy, I.P., Moeslein, K.M., Nambisan, S., Piller, F.T., Radziwon, A., Rossi-Lamastra, C., Sims, J. and Ter Wal, A.L.J. (2017), "The open innovation research landscape: established perspectives and emerging themes across different levels of analysis", Industry and Innovation, Vol. 24 No. 1, pp. 8-40.

Bouquet, C. and Birkinshaw, J. (2008), "Weight versus voice: how foreign subsidiaries gain attention from corporate headquarters", Academy of Management Journal, Vol. 51 No. 3, pp. 577-601.

Bunduchi, R. (2017), "Legitimacy-seeking mechanisms in product innovation: a qualitative study", Journal of Product Innovation Management, Vol. 34 No. 3, pp. 315-342.

Chen, Q., Magnusson, M. and Bjork, J. (2020), "Collective firm-internal online idea development: exploring the impact of feedback timeliness and knowledge overlap", European Journal of Innovation Management, Vol. 23 No. 1, pp. 13-39.

Cho, S.T. and Hambrick, D.C. (2006), "Attention as the mediator between top management team characteristics and strategic change: the case of airline deregulation", Organization Science, Vol. 17 No. 4, pp. 453-469.

Colombo, M.G., Laursen, K., Magnusson, M. and Rossi-Lamastra, C. (2011), "Organizing inter- and intra-firm networks: what is the impact on innovation performance?", Industry and Innovation, Vol. 18 No. 6, pp. 531-538.

Cummings, J.N. and Haas, M.R. (2012), "So many teams, so little time: time allocation matters in geographically dispersed teams", Journal of Organizational Behavior, Vol. 33 No. 1, pp. 316-341.

Dahlander, L. and Piezunka, H. (2014), "Open to suggestion: how organizations elicit suggestions through proactive and reactive attention”, Research Policy, Vol. 43 No. 5, pp. 812-827.

Dahlander, L. and Magnusson, M. (2005), "Relationships between open source software companies and communities: observations from Nordic firms", Research Policy, Vol. 34 No. 4, pp. 481-493.

Dane, E. (2013), "Things seen and unseen: investigating experience-based qualities of attention in a dynamic work setting", Organization Studies, Vol. 34 No. 1, pp. 45-78.

Di Gangi, P.M. and Wasko, M. (2009), "Steal my idea. Organizational adoption of user innovations from a user innovation community: a case study of Dell IdeaStorm”, Decision Support Systems, Vol. 48 No. 1, pp. 303-312.

Di Gangi, P., Wasko, M. and Hooker, R. (2010), “Getting customers' ideas to work for you: learning from Dell how to succeed with online user innovation communities", MIS Quarterly Executive, Vol. 9 No. 4, pp. 213-228.

Ghezzi, A., Gabelloni, D., Martini, A. and Natalicchio, A. (2018), "Crowdsourcing: a review and suggestions for future research", International Journal of Management Reviews, Vol. 20, pp. 343-363. 
Gloor, P. (2017), Swarm Leadership and the Collective Mind: Using Collaborative Innovation Networks to Build a Better Business, Emerald Publishing, Bingley.

Haas, M.R., Criscuolo, P. and George, G. (2015), "Which problems to solve? Online knowledge sharing and attention allocation in organizations", Academy of Management Journal, Vol.58 No. 3, pp. 680-711.

Idea survival in internal crowdsourcing

Hannan, M.T. and Freeman, J.H. (1989), Organizational Ecology, Harvard University Press, Cambridge.

Hansen, M.T. and Haas, M.R. (2001), "Competing for attention in knowledge markets: electronic document dissemination in a management consulting company", Administrative Science Quarterly, Vol. 46 No. 1, pp. 1-28.

Hayes, A.F. (2006), “A primer on multilevel modeling”, Human Communication Research, Vol. 32 No. 4, pp. 385-410.

Jeppesen, L.B. and Lakhani, K.R. (2010), "Marginality and problem-solving effectiveness in broadcast search”, Organization Science, Vol. 21 No. 5, pp. 1016-1033.

Kijkuit, B. and van den Ende, J. (2010), "With a little help from our colleagues: a longitudinal study of social networks for innovation", Organization Studies, Vol. 31 No. 4, pp. 451-479.

Knudsen, M. (2011), "Forms of inattentiveness: the production of blindness in the development of a technology for the observation of quality in health services", Organization Studies, Vol. 32 No. 7, pp. 963-989.

Malhotra, A., Majchrzak, A., Kesebi, L. and Looram, S. (2017), "Developing innovative solutions through internal crowdsourcing", MIT Sloan Management Review, Vol. 73 No. 4, pp. 72-79.

Malhotra, A. and Majchrzak, A. (2014), "Managing crowds in innovation challenges", California Management Review, Vol. 56 No. 4, pp. 103-124.

Majchrzak, A. and Malhotra, A. (2013), "Towards an information systems perspective and research agenda on crowdsourcing for innovation”, The Journal of Strategic Information Systems, Vol. 22 No. 4, pp. 257-268.

Nigam, A. and Ocasio, W. (2010), "Event attention, environmental sensemaking, and change in institutional logics: an inductive analysis of the effects of public attention to clinton's health care reform initiative", Organization Science, Vol. 21 No. 4, pp. 823-841.

Ng, E.S.W., Carpenter, J.R., Goldstein, H. and Rasbash, J. (2006), "Estimation in generalised linear mixed models with binary outcomes by simulated maximum likelihood", Statistical Modelling, Vol. 6 No. 1, pp. 23-42.

O'Leary, D.E. (2016), "On the relationship between number of votes and sentiment in crowdsourcing ideas and comments for innovation: a case study of Canada's digital compass", Decision Support Systems, Vol. 88 No. 3, pp. 28-37.

O'Mahony, S. and Lakhani, K. (2011), "Organizations in the shadow of communities", Research in the Sociology of Organizations, Vol. 33, pp. 3-36.

Ocasio, W. (1997), “Toward an attention-based view of the firm”, Strategic Management Journal, Vol. 18 No. S1, pp. 187-206.

Ocasio, W. (2011), “Attention to attention”, Organization Science, Vol. 22 No. 5, pp. 1286-1296.

Palmiè, M., Lingens, B. and Gassmann, O. (2015), "Towards an attention-based view of technology decisions", R\&D Management, Vol. 46 No. 4, pp. 781-796.

Piezunka, H. and Dahlander, L. (2015), "Distant search narrow attention: how crowding alters organizations' filtering of suggestions in crowdsourcing", Academy of Management Journal, Vol. 58 No. 3, pp. 856-880.

Podolny, J.M., Stuart, T.E. and Hannan, M. (1996), "Networks, knowledge, and niches: competition in the worldwide semiconductor industry, 1984-1991", American Journal of Sociology, Vol. 102 No. 3, pp. 659-689.

Rabe-Hesketh, S. and Skrondal, A. (2008), Multilevel and Longitudinal Modeling Using Stata, 2nd ed., Stata Press. 
Reitzig, M. and Sorenson, O. (2013), "Biases in the selection stage of bottom-up strategy formulation", Strategic Management Journal, Vol. 34 No. 7, pp. 782-799.

Rueda, M.R., Posner, M.L. and Rothbart, M.K. (2005), "The development of executive attention: contributions to the emergence of self-regulation”, Developmental Neuropsychology, Vol. 28 No. 1, pp. 573-594.

Schemmann, A.M., Herrmann, A.M., Chappin, M.M.H. and Heimeriks, G.J. (2016), "Crowdsourcing ideas: involving ordinary users in the ideation phase of new product development", Research Policy, Vol. 45 No. 6, pp. 1145-1154.

Schulze, A. and Hoegl, M. (2008), "Organizational knowledge creation and the generation of new product ideas: a behavioral approach”, Research Policy, Vol. 37 No. 9, pp. 1742-1750.

Shapiro, C. and Varian, H.R. (1999), Information Rules: A Strategic Guide to the Network Economy, Harvard Business School Press, Boston, MA.

Shrout, P.E. and Bolger, N. (2002), "Mediation in experimental and nonexperimental studies: new procedures and recommendations", Psychological Methods, Vol. 7 No. 4, pp. 422-445.

Sobel, M.E. (1982), "Asymptotic intervals for indirect effects in structural equations models", in Leinhart, S. (Ed.), Sociological Methodology: 290-312, Jossey-Bass, San Francisco.

Sullivan, B.N. (2010), "Competition and beyond: problems and attention allocation in organizational rulemaking processes", Organization Science, Vol. 21 No. 2, pp. 432-450.

Van den Ende, J., Frederiksen, L. and Prencipe, A. (2014), "The front end of innovation: organizing search for ideas", Journal of Product Innovation Management, Vol. 32 No. 4, pp. $482-487$.

Van de Ven, A.H. (1986), "Central problems in the management of innovation”, Management Science, Vol. 32 No. 5, pp. 590-607.

Van Knippenberg, D., Dahlander, L., Haas, M. and George, G. (2015), "Information, attention, and decision making", Academy of Management Journal, Vol. 58 No. 3, pp. 649-657.

Weick, K.E. and Sutcliffe, K.F. (2006), "Mindfulness and the quality of attention", Organization Science, Vol. 17 No. 3, pp. 514-525.

Zhu, J.J., Li, S.Y. and Andrews, M. (2017), "Ideator expertise and cocreator inputs in crowdsourcingbased new product development", Journal of Product Innovation Management, Vol. 34 No. 5, pp. 598-616.

\section{Corresponding author}

Fausto Di Vincenzo can be contacted at: fausto.divincenzo@unich.it

For instructions on how to order reprints of this article, please visit our website:

www.emeraldgrouppublishing.com/licensing/reprints.htm

Or contact us for further details: permissions@emeraldinsight.com 